\title{
Degradation and Damage of Composite Materials in Marine Environment
}

\author{
Goran VIZENTIN, Goran VUKELIC* \\ University of Rijeka, Faculty of Maritime Studies, Studentska 2, HR51000 Rijeka, Croatia \\ crossref http://dx.doi.org/10.5755/j01.ms.26.3.22950
}

Received 13 March 2019; accepted 06 May 2019

\begin{abstract}
In spite the fact that composite materials have been in use in the maritime sector for over a half of century, classification societies regulations tend to limit the usage of composites at the larger scale. One of the reasons for such strict class rules is a lack of comprehensive analytical and numerical models representing the behaviour of composites in the sea environment. Understanding the process of degradation and damage of composite materials assisted by sea environment a crucial step in building such a model. This paper aims to give a critical review of the research advancements in assessments of the sea environment influence on the degradation of mechanical properties of composites with a special emphasis on developed models of processes containing water and moisture entering composite inner structure. The list of major references in the last five years is given and suggestions for future research are discussed.

Keywords: marine composites, water diffusion, moistening process, degradation process.
\end{abstract}

\section{INTRODUCTION}

Composite materials have been used in maritime structures for several decades up to the present time, with application ranging from leisure boats to military vessels and structures (offshore, renewable energy) [1-4]. Composites are also used for specific elements on ships and structures such as superstructures, deck elements, bulkheads, propulsion systems elements, piping etc.

A more extensive and broader application in the maritime sector has been made difficult due to incomplete or non-existing rules of classification societies with respect to durability and environment influence issues. The lack of all-encompassing understanding of durability of composite materials under specific environmental and load conditions is the cause of a slow progressing application of composites in marine industry (i.e. ships and offshore structures) [5].

The most recent versions of class standards take into account the possibility of composite materials application as construction materials [6-9]. The standards obligatory in the maritime sector prescribe temperature, water, chemicals and UV-radiation as environmental conditions that are considered in the assessment of environmental influence on the mechanical properties of composites. The materials taken into account are reduced to composites using resins with glass transition temperatures ranging below $150{ }^{\circ} \mathrm{C}$ [10]. Standards recommend "documenting test results" in order to determine the behaviour of the material, thus emphasizing the lack of reliable analytical or numerical models in this field or research.

In addition, shipbuilding is a relatively conservative industry field not prone to quick adaptation of new technologies and materials applications. However, the presence of composites in the shipbuilding is steadily increasing and even dominating as construction materials for small crafts $(<50 \mathrm{~m})$ in the new millennium [11]. The

\footnotetext{
${ }^{*}$ Corresponding author. Tel.: +385-51-338411; fax: +385-51-336755.

E-mail address: gvukelic@pfri.hr(G. Vukelic)
}

need for updated and more encompassing regulations regarding acceptance of composite materials as a worthy material in general, as well as maritime applications is evident [12].

The aggressive influence of the marine environment is a significant factor in the design of maritime structures regardless of the material used. The application possibilities for composite materials are based on a welldefined and in-practice proven mechanical model of their behaviour under various load scenarios characteristic for vessels, as well as the influences of the aggressive marine environment. Example of such approach is, for instance, experimental research [13] of the composites exposed to seawater weathering followed by fire and/or heat damage, typical for marine environment. Some research can be performed numerically, e.g. estimating reliability of filamentary composites in marine environment based on sensitivity analysis [14].

Given all that, complete comprehension of the adsorption and diffusion process of water in the matrix is a crucial process to be understood. Just then, environmental effects could be numerically modelled and the composite degradation process integrated into the design process of marine structures. Finite element (FE) analysis proves here as an indispensable tool in numerical modelling of mechanical behaviour of any structure.

In order to incorporate the effects of water diffusion in FE analysis, input parameters are needed so experimental testing is often used to extrapolate water absorption and diffusion process parameters that can be used in analytical and numerical analysis [15]. The aging effects due to moisture intake must be coupled with mechanical loading effects so a complete numerical model can be developed.

All of the above-mentioned issues served as a motivation in writing this review article, which aims to present recent relevant work in this field of research. The goal is to give a critical overview of the current state of the research as well as to outline possible future directions of research advancements. Fundamental work on this topic can be tracked through provided references. 


\section{MOISTENING AND SOAKING PROCESS OF COMPOSITES}

Composite materials are composed of a polymer matrix and reinforcing fibres. The function of the matrix is to hold the load bearing fibres composed in a desired shape needed for the structural element, whilst the fibre provides directional material strength. The combination of the matrix and fibres is referred to as laminate. When composite materials are used in humid or wet environment, moisture adsorption becomes an issue as it changes mechanical properties of the laminate. The matrix is structurally modelled, in accordance to Flory-Huggins theory, as lattice of cells occupied by the polymer or solvent molecules. During the process of polymer chain forming, some of the cells are not occupied by the polymer molecules. These vacancies determine material porosity and permeability and enable penetration of gas of fluid molecules present in to the environment into the material itself.

The parameters that have the most significant influence on moisture intake process are time, matrix chemical composition, percentage of environmental moisture content, environmental temperature, $\mathrm{pH}$ factor, $\mathrm{UV}$ radiation and pressure.

This penetration of fluids into the matrix is usually modelled according the one-dimensional Fick's law from the initial adsorption to the saturation level [16-19]. This law assumes an infinite plate model for the laminate, which is not satisfactory for thick composites. The diffusion and moisture intake in thick laminates has to be modelled with three-dimensional models [20].

It is assumed that a solute will move from regions of high concentration to a region of low concentration across a concentration gradient and the diffusion process of water molecules into the composite material is correlated to diffusion of water in a membrane. It has been observed by various authors, [18,21-23] that the adsorption and diffusion in composite materials may not conform to the Fick's law when the composite material is subjected to hydrostatic pressure, various moisture concentration and temperature values.

Osmosis it on of the process by which water penetrates the matrix and after the penetration dissolves any soluble material thus forming solution volumes (pockets) which exerts pressure to the surrounding material as it continues to grow, finally resulting in stresses that cause delamination of the composite material layers.

The absorbed water can enable physical and chemical degradation, which influences the mechanical behaviour of polymer composite by affecting mechanical properties of the material $[24,25]$.

A kinetic model of water absorption in polymer materials has been proposed by Gilormini and Verdu [26] based on the idea of hydrogen bonding to polymer matrix, which includes non-Fickian diffusion.

The diffusion of fluids in a fibre reinforced composite material can be characterized as anisotropic as the diffusion in the fibre direction is more intensive than in the fibre transverse direction [16].

\section{SEA ENVIRONMENT INFLUENCE ON COMPOSITES DEGRADATION}

The most commonly used resins for composite materials in the marine industries are polyester, vinyl ester and epoxy. The reinforcing fibres are usually made of glass, carbon or para-aramid. The composite material combinations that have been mostly used are Glass Reinforced Polyester (GRP), aramid fibre composites and carbon fibre reinforced epoxy composites.

The absorbed seawater has a significant influence on the composite materials mechanical properties. The water molecules react with the matrix polymer molecules causing plasticization, which in turn causes matrix cracking, voids in the matrix that represent potential fatigue cracks starting points, delamination and blistering [19].

All of these occurrences represent serious structural issues, which makes understanding and modelling this phenomenon of crucial importance.

The usual procedure used to assess the long-term influence of seawater on the mechanical characteristics and dynamic response of composite material structures is soaking standardized coupons in water, monitoring the amount of absorbed water by periodic weighing until saturation (no significant further increase in coupon mass) and final comparison of dry and wet coupon mechanical properties [18]. This procedure is time consuming. Accelerated test methods have been developed in order to reduce the necessary testing time [27-30]. These methods are based on the idea of heating the water in order to achieve a faster diffusion process, hence reducing the time needed to reach the water saturation of the material. The testing is performed in aging chambers with controlled conditions of parameters monitored, usually temperature, humidity and UV-radiation. Relevant changes within the material that cause variations in mechanical properties are monitored using spectroscopy, Dynamic Mechanical Analysis (DMA), Scanning Electron Microscopy (SEM). Mass variations are indicative of the level of moisture content in the material [31].

Hakansson et.al. [32] presented a parametric study based on Det Norske Veritas (DNV) rules to determine which types of composite material are most suitable for weight/cost minimization of ships. The authors concluded that a paradigm shift is needed in ship construction as the early stages of design open more opportunities for composites materials compared to classically used steel and aluminium. In addition, illogicalities in the DNV class regulations regarding minimum thickness of composite structural elements requirements have been highlighted, emphasizing the need for further work on the regulations in order to accommodate the applications of composite materials.

Grogan et.al. [33] defined the influence of microstructure and hydrostatic pressure in composites that are suitable for use in tidal energy devices construction. Microstructural defects, referred to as voids that can happen during production of composites have a significant effect on the moisture diffusion rate and on the total amount of absorbed water. The research was done for four materials, namely a glass fibre powder epoxy (GFE), a carbon fibre powder epoxy (CFE), glass fibre Ampreg 
(GFA) epoxy and a chopped fibre GF PEEK. Their results have shown that hydrostatic pressure increases the initial water absorption rate but does not affect the final water uptake. The changes in mass and volume remained unchanged after drying indicating that the material has suffered a permanent change in properties, which has repercussions to the device performances. The need for further testing and research due to the complexity of the water absorption process was once again stressed.

\section{ANALYTICAL AND NUMERICAL PROCESS MODELING}

Combination of theoretical knowledge and experimental results are needed to generate a complete numerical model that can be integrated into standard FEA procedures to enable the numerical simulation for structures constructed of composite materials.

Analytical methods for modelling the moisture absorption process in pure polymers and consecutive change of their mechanical properties have been developed $[15-17,34]$.

However, analytical models for effects of moisture absorption on mechanical properties of composite materials are somewhat sparse. Pan and Zhong [35] have proposed the method of hybridization of the composite material with natural fibres by adding synthetic hydrophobic fibres into the composite and developed an accompanying analytical linear constitutive model of such material. Thermodynamic principles have been used in order to model the progression of moisture absorption and degradation of mechanical properties.

Akil et.al. [36] investigated the jute and jute/glass hybrid reinforced polyester composites degradation under combined water absorption and moderate temperature influence. A deviation from Fickian absorption model and a reduction in strength and elastic modulus was observed. The glass fibres proved to reduce the degradation of mechanical properties due to their resistance to water absorption. Acoustic emission measurements and SEM observations indicated that fibre/matrix interface weakening is the main damage mechanism induced by water ageing.

Peret et.al. [37] used the classical finite element method to numerically model the solution of uncoupled mechanical-water diffusion boundary problems at the microscopic level for two polymer resins reinforced with hydrophobic glass and carbon fibres. The authors concluded that further research is needed in order to analyse diffusion-mechanical couplings and that scale transition methods have to be developed to take into account microscopic details influencing material behaviour at a higher scale. In a more recent work [38] the same group of authors modelled the hygro-mechanical coupling effect using the semi-empirical free volume theory comparing pure resin mechanically loaded sample results to unidirectional laminate sample behaviour, comparing the classical Fick's law and a strain-dependent diffusivity based on the afore mentioned free volume theory. This approach has shown "discrepancies between the two models during the transient part of the moisture diffusion process", with further research still needed.
Pan and Zhong [39] have developed an analytical micromechanical model, which describes the change of mechanical properties of composites with natural fibres, which includes a damage variable, all for randomly oriented straight fibres. The author has verified on examples that a stiffer matrix can reduce moisture absorption in the material, hence reducing the loss of mechanical properties of the composite.

Joliff et.al. [40] analysed water diffusion in unidirectional composites taking into account the fibre/matrix interphase, which has different properties than the matrix, the effect that fibres arrangement heterogeneity and contact between fibres has on the water diffusion characteristics. The data was verified experimentally, analytically and numerically. This research has shown that particular attention must be given to the meshing process during FE analysis, as there are three distinctive regions in the composite material, namely the matrix, the fibres and the interphase, which all need different element sizes. The research has led to the conclusion that a simplified microstructure cannot be used to model the water diffusion process in unidirectional composites. Numerical structure model must be based on a realistic structure in order to yield a reliable model for the water diffusion process in composite materials.

Recent testing proved that a coupling effect of water diffusion and mechanical stresses has a significant influence on composite materials mechanical properties degradation.

Meng et.al. researched the time dependencies of moisture diffusion and stress distribution in in carbon fibre reinforced polymeric (CFRP) composites using experimental data and FE analysis [41]. The research resulted in a multiscale $3 \mathrm{D}$ numerical model that can be used to evaluate the stresses occurring in the interface between the matrix and fibres. In this case, the moisture diffusion process has been modelled using a realistic $2 \mathrm{D}$ numerical on the micro scale. The coupling effect of moisture ingression and consequential induced stresses has been confirmed by SEM analysis, which has shown fractures in the matrix/fibre interface zones.

Wang et.al. developed an equivalent model in order to obtain a coefficient of hygrothermal expansion in the composite material and a multi-scale model for composite plates strain and stress calculation [42]. The second Fick's law was used as basis to model the water absorption process and the coupling behaviour to stress. The verification of the results was done experimentally and numerically. The numerical model is based on a representative unit cell, which enables the calculation of strain and stress in both fibre and matrix.

Pour-Ghaz et.al. [43] analysed the coupled effects of mechanical and environmental loading on Glass Fibre Reinforced Polymers (GFRP) by loading the samples in heated fresh and salt water at various load levels up to $30 \%$ of their ultimate tensile strength. Interestingly, the authors concluded: "this indicates that no synergistic effect on the degradation rate of pultruded GFRP exists between mechanical and environmental loading at stress levels encountered during the service life of FRP structures". This effect was possible due to two process occurring in the same time in this case, the degradation of mechanical 
properties and the increase of the strength after post-curing at elevated temperature. This process of conditioning under constant tensile load has been deemed very expensive and time consuming by the authors themselves. The research for higher loads and longer curing times remains to be undertaken.

Joliff et.al. [44] have investigated the influence of the interphase areas in unidirectional composites on the water diffusion process, as well as mechanical properties degradation using experimental. Analytical and numerical analysis. The structural modelling of the interphase was done on the microscale level. The findings of this research indicates that the water diffusion coefficient is about five times higher in the interphase area than in the matrix. The results did not show significant influence of the modulus change around the fibres.

Humeau et.al. [45] performed experimental research of water diffusion in carbon/epoxy composites subjected to static tensile stress. This research emphasizes the lack of experimental data and analytical theories for fully coupled behaviour of the water absorption/diffusion process and mechanical stress. The authors concluded that testing these two effects sequentially gives a wrong impression of weak correlation on mechanical degradation, whereas when water diffusion and stress are simultaneously applied to composites large effects can be observed. The diffusion process can no longer be simulated as Fickian and resulting defects can be cause of premature failures. These coupling effects are essential for composite structures lifetime predictions.

$\mathrm{Lu}$ et.al. concentrated their research on various types of glass reinforced polymer (GRP) composites exposed to UV radiation, water condensation and high temperature, proposing a new synergistic composites aging model [46]. The author has indicated that "the surface erosion of polymer matrices of the GRPs by combined UV and water condensation creates the most effective condition for small polymer particles formed by UV to be subsequently removed by water condensation exposing fresh still undamaged surfaces to further UV degradation".

Fang et.al. have proposed a method for monitoring the effect of seawater aging in glass reinforced polymer (GRFP) composite [47]. The method proposes adding socalled quantum dots labeled on the glass fibre by chemical bond. A quantum dots is a fluorescent labelling agent that can be used in sensing water absorption into the material. Seawater inside the composite material causes separation of fibres and matrix, which in turn exposes the quantum dot the water causing the loss of fluorescence, indicative of water intrusion.

Chen et.el. investigated the influence of hydrostatic pressure on the water absorption process [48]. The result had shown that the water absorption rate variated with pressure showing two distinctive cases. For smaller values $(<3 \mathrm{MPa})$ the increase of pressure caused a reduction in the absorption of water while for higher values $(3-5 \mathrm{MPa})$ increase of pressure caused a more intensive absorption.

\section{DISCUSSION AND CONCLUSION}

Summarizing, a broader application of composite in the maritime sector has been limited by relatively high initial costs and fire regulations. The beneficial factors that can enable a broader use of composites is the ever stricter environmental requirements regarding fuel emissions when the smaller weight of composite materials comparing to traditional materials gains importance. Compared to traditional materials used in shipbuilding (steel, aluminium alloy and wood) composite materials offer the possibility of significant structural, maintenance/exploitation and economical aspects improvement due to their specific mechanical characteristics. The most important areas of improvement compared to traditional materials are weight reduction (low material density), corrosion resistance and flexibility in shape forming of mechanical parts and structural elements.

Still, class regulations require comparative studies with traditional materials.

Modelling the behaviour of composite materials under mechanical loads and establishing their failure modes is a rather complicated task due to the pronounced material heterogeneity and anisotropy. In addition to different matrix and fibre mechanical properties, the interphase areas that form in the fibre/matrix bonding zone have to be taken into account as these areas exhibit yet another change in material characteristics. Current research efforts seem to be concentrated on either experimental, analytical or numerical modelling of the environmental influence on the mechanical properties of composites.

Additional environmental effects, such as moisture and/or water absorption influence on the mechanical properties of the composites make the structural analysis even more complicated. This influence is especially significant for maritime structures, which are constantly in contact or completely submerged in seawater. There is currently no comprehensive general model for composite materials that would enable to incorporate the water intake effects on composites in standard numerical analysis procedures. Furthermore, research that takes into account the coupling effect of water absorption and stress is in its initial phase.

Another specific issue in numerical modelling of composites is that a realistic approach is inevitable, i.e. actual structure made of a specific composite needs to be modelled in order to correctly ascertain its behaviour. This numerical model has to take into account the matrix/fibre interphase that exhibits high water diffusivity.

Moreover, not only that numerical models need to be specific, but also experiments that are used for verification of analytical and numerical solutions need to be tailored to specific type of composite material. Consequently, experimentally obtained results tend to be valid only in specific range of composite material structure. All that adds to the cost and duration of experimental testing, limiting greater usage of composites in a traditionally conservative and cost-conscious marine industry. Bearing in mind that mechanical behaviour of composites relies heavily on material structure as well that the adsorption process is strongly material dependent, it can be concluded that a theory that would incorporate general composite behaviour model will not be easily reached. It is most probable that this generalized model will not be reached in a single step, but a continuous, small-increment step toward it will be needed. Nevertheless, the idea of a 
generalized model is certainly worth investigating during further research efforts.

\section{Acknowledgments}

This work has been supported by the University of Rijeka under the project numbers: uniri-technic-18-200 "Failure analysis of materials in marine environment" and uniri-technic-18-42 "Investigation, analysis and modelling the behaviour of structural elements stressed at room and high temperatures". This work has been supported by the Croatian Science Foundation under the project IP-2020-02-3294.

\section{REFERENCES}

1. Sano, T., Srivatsan, T.S., Peretti, M.W. Advanced Composites for Aerospace, Marine and Land Applications, Springer International Publishing Cham, 2016, ISBN 978-3319-48592-8. https://doi.org/10.1007/978-3-319-48096-1

2. Mouritz, A., Gellert, E., Burchill, P., Challis, K. Review of Advanced Composite Structures for Naval Ships and Submarines Composite Structures 53 2001: pp $21-42$. https://doi.org/10.1016/S0263-8223(00)00175-6

3. Shenoi, R.A., Dulieu-Barton, J.M., Quinn, S., Blake, J.I.R., Boyd, S.W. Composite Materials for Marine Applications: Key Challenges for the Future. In Composite Materials, Springer London, London, 2011: pp. 69-89. https://doi.org/10.1007/978-0-85729-166-0_3

4. Razavi Setvati, M., Mustaffa, Z., Shafiq, N., Syed, Z.I. A Review on Composite Materials for Offshore Structures Proceedings of the Volume 5: Materials Technology, Petroleum Technology, ASME, 2014, p. V005T03A016. https://doi.org/10.1115/OMAE2014-23542

5. Wang, J., GangaRao, H., Liang, R., Liu, W. Durability and Prediction Models of Fibre-Reinforced Polymer Composites Under Various Environmental Conditions: A Critical Review Journal of Reinforced Plastics and Composites 35 2016: pp 179-211. https://doi.org/10.1177/0731684415610920

6. Det Norske Veritas DNV GL rules for classification: High speed and light craft (RU-HSLC), Oslo, 2018.

7. Lloyds Register Rules and Regulations for the Classification of Special Service Craft (July 2011), 2011

8. American Bureau of Shipping (ABS) Rules for materials and welding-Part 2 Aluminum and Fibre Reinforced Plastics (FRP), 2018.

9. Bureau Veritas NR 546 DT R02 - Hull in Composite Materials and Plywood, Material Approval, Design Principles, Construction and Survey 2018.

10. Det Norske Veritas DNV GL AS DNVGL-ST-C501 Composite components, 2017.

11. Neşer, G. Polymer Based Composites in Marine Use: History and Future Trends Procedia Engineering 194 2017: pp 19-24. https://doi.org/10.1016/j.proeng.2017.08.111

12. Stevens, R., Quinn, S., Veal, R., Gerrard, S., Tsimplis, M., $\quad$ Dulieu-Barton, J., Thomsen, $\mathbf{O}$. Modernising Composite Materials Regulations: A Position Paper, University of Southampton, UK, 2017.

13. Elmushyakhi, A., Toubia, E.A., Morgan, A.B. Post-Fire Failure Mechanisms of Seawater-Accelerated Weathering
Composites for Coastal and Marine Structures

Marine

Structures 63 2019: pp. 304-317.

https://doi.org/10.1016/ j.marstruc.2018.10.004

14. Hocine, A., Maizia, A., Ghouaoula, A., Dehmous, H. Reliability Prediction of Composite Tubular Structure Under Mechanical Loading by Finite Element Method Journal of Failure Analysis and Prevention 18 2018: pp. 1439 - 1446.

https://doi.org/10.1007/s11668-018-0536-Z

15. Gagani, A.I., $\quad$ Krauklis, A.E., $\quad$ Echtermeyer, A.T. Orthotropic Fluid Diffusion in Composite Marine Structures. Experimental Procedure, Analytical and Numerical Modelling of Plates, Rods and Pipes Composites Part A: Applied Science and Manufacturing 115 2018: pp. 196-205. https://doi.org/10.1016/j.compositesa.2018.09.026

16. Gagani, A., Fan, Y., Muliana, A.H., Echtermeyer, A.T. Micromechanical Modeling of Anisotropic Water Diffusion in Glass Fibre Epoxy Reinforced Composites Journal of Composite Materials 52 2018: pp. 2321-2335. https://doi.org/10.1177/0021998317744649

17. Gagani, A.I., Echtermeyer, A.T. Influence of Delaminations on Fluid Diffusion in Multidirectional Composite Laminates - Theory and Experiments International Journal of Solids and Structures 158 2019: pp. $232-242$. https://doi.org/10.1016/j.ijsolstr.2018.09.009

18. Davies, P. Environmental Degradation of Composites for Marine Structures: New Materials and New Applications Philosophical Transactions of the Royal Society A: Mathematical, Physical and Engineering Sciences 374 (2071) 2016: pp. 1 -13 https://doi.org/10.1098/rsta.2015.0272

19. Musto, P., Galizia, M., Scherillo, G., Mensitieri, G. Water Sorption Thermodynamics in Polymer Matrices, chapter in Durability of Composites in a Marine Environment, Springer, Dordrecht, 2014: pp. 15 - 45. https://doi.org/10.1007/978-94-007-7417-9_2

20. Pierron, F., Poirette, Y., Vautrin, A. A Novel Procedure for Identification of 3D Moisture Diffusion Parameters on Thick Composites: Theory, Validation and Experimental Results Journal of Composite Materials $36(19)$ 2002: pp. 2219-2243. https://doi.org/10.1177/0021998302036019003

21. Summerscales, J. Durability of Composites in the Marine Environment, (chapter in) Durability of Composites in a Marine Environment, Springer, Dordrecht, 2014: pp. 1-13. https://doi.org/10.1007/978-94-007-7417-9_1

22. Jiang, X., Kolstein, H., Bijlaard, F.S.K. Moisture Diffusion in Glass-Fibre-Reinforced Polymer Composite Bridge Under Hot/Wet Environment Composites Part B: Engineering 45 (1) 2013: pp. 407-416. https://doi.org/10.1016/j.compositesb.2012.04.067

23. Wong, T.C., Broutman, L.J. Water in Epoxy Resins Part II. Diffusion Mechanism Polymer Engineering and Science 25 (9) 1985: pp. 529-534. https://doi.org/10.1002/pen.760250904

24. Weitsman, Y.J., Elahi, M. Effects of Fluids on the Deformation, Strength and Durability of Polymeric Composites - An Overview Mechanics of Time-Dependent Materials 4 (2) 2000: pp. 107-126.

25. Weitsman, Y.J. Fluid Effects in Polymers and Polymeric Composites, Mechanical Engineering Series, Springer US: Boston, MA, 2012, ISBN 978-1-4614-1058-4. https://doi.org/10.1023/A:1009838128526 
26. Gilormini, P., Verdu, J. On the Role of Hydrogen Bonding on Water Absorption in Polymers Polymer 142 2018: pp. $164-169$. https://doi.org/10.1016/j.polymer.2018.03.033

27. Miyano, Y., Nakada, M., Ichimura, J., Hayakawa, E. Accelerated Testing for Long-Term Strength of Innovative CFRP Laminates for Marine Use Composites Part B: Engineering 39 (1) 2008: pp. 5-12. https://doi.org/10.1016/j.compositesb.2007.02.009

28. Afshar, A., Liao, H.T., Chiang, F., Korach, C.S. Timedependent Changes in Mechanical Properties of Carbon Fibre Vinyl Ester Composites Exposed to Marine Environments Composite Structures 144 2016: pp. $80-85$. https://doi.org/10.1016/j.compstruct.2016.02.053

29. Alessi, S., Pitarresi, G., Spadaro, G. Effect of Hydrothermal Ageing on the Thermal and Delamination Fracture Behaviour of CFRP Composites Composites Part B Engineering 67 2014: pp. 145-153. https://doi.org/10.1016/j.compositesb.2014.06.006

30. Park, H., Choi, J., Kim, B., Yang, S., Shin, H., Cho, M. Toward the Constitutive Modeling of Epoxy Matrix: Temperature-Accelerated Quasi-Static Molecular Simulations Consistent with the Experimental Test Composites Part B Engineering 142 2018: pp. 131-141. https://doi.org/10.1016/j.compositesb.2018.01.018

31. Cysne Barbosa, A.P., P. Fulco, A.P., S.S. Guerra, E., K. Arakaki, F., Tosatto, M., B. Costa, M.C., D. Melo, J.D. Accelerated Aging Effects on Carbon Fibre/Epoxy Composites Composites Part B: Engineering 110 2017: pp. $298-306$.

https://doi.org/10.1016/j.compositesb.2016.11.004

32. Håkansson, M., Johnson, E., Ringsberg, J.W. Cost and Weight of Composite Ship Structures: A Parametric Study Based on Det Norske Veritas Rules Proceedings of the Institution of Mechanical Engineers, Part M: Journal of Engineering for the Maritime Environment 232 (3) 2018: pp. 331-350.

https://doi.org/10.1177/1475090217693419

33. Grogan, D., Flanagan, M., Walls, M., Leen, S., Doyle, A., Harrison, N., Mamalis, D., Goggins, J. Influence of Microstructural Defects and Hydrostatic Pressure on Water Absorption in Composite Materials for Tidal Energy Journal of Composite Materials $52(21)$ 2018: pp 2899-2917. https://doi.org/10.1177/0021998318755428

34. Melo, R.Q.C., Santos, W.R.G., Barbosa de Lima, A.G., Lima, W.M.P.B., $\quad$ Silva, J.V., $\quad$ Farias, R.P. Water Absorption Process in Polymer Composites: Theory Analysis and Applications, (chapter in) Transport Phenomena in Multiphase Systems, Springer, Cham, 2018: pp. 219-249. https://doi.org/10.1007/978-3-319-91062-8_7

35. Pan, Y., Zhong, Z. The Effect of Hybridization on Moisture Absorption and Mechanical Degradation of Natural Fibre Composites: An Analytical Approach Composites Science and Technology 110 2015: pp 132-137. https://doi.org/10.1016/j.compscitech.2015.02.005

36. Akil, H.M., Santulli, C., Sarasini, F., Tirillò, J., Valente, T. Environmental Effects on the Mechanical Behaviour of Pultruded Jute/Glass Fibre-Reinforced Polyester Hybrid Composites Composites Science and Technology 94 2014: pp. 62-70. https://doi.org/10.1016/j.compscitech.2014.01.017
37. Peret, T., Clement, A., Freour, S., Jacquemin, F. Numerical Transient Hygro-Elastic Analyses of Reinforced Fickian and Non-Fickian Polymers Composite Structures 116 2014: pp. $395-403$.

https://doi.org/10.1016/j.compstruct.2014.05.026

38. Peret, T., Clement, A., Freour, S., Jacquemin, F. Effect of Mechanical States on Water Diffusion Based on the Free Volume Theory: Numerical Study of Polymers and Laminates Used in Marine Application Composites Part B: Engineering 118 2017: pp. 54-66. https://doi.org/10.1016/j.compositesb.2017.02.046

39. Pan, Y., Zhong, Z. A Micromechanical Model for the Mechanical Degradation of Natural Fibre Reinforced Composites Induced by Moisture Absorption Mechanics of Materials 85 2015: pp. 7-15.

https://doi.org/10.1016/j.mechmat.2015.02.001

40. Joliff, Y., Belec, L., Chailan, J.F. Modified Water Diffusion Kinetics in an Unidirectional Glass/Fibre Composite Due to the Interphase Area: Experimental, Analytical and Numerical Approach Composite Structures 97 2013: pp. 296-303.

https://doi.org/10.1016/j.compstruct.2012.09.044

41. Meng, M., Rizvi, M.J., Le, H.R., Grove, S.M. Multi-scale Modelling of Moisture Diffusion Coupled with Stress Distribution in CFRP Laminated Composites Composite Structures 138 2016: pp. 295-304. https://doi.org/10.1016/j.compstruct.2015.11.028

42. Wang, J., Dai, F., Ma, L. A Multi-Scale Moisture Diffusion Coupled with Stress Model for Composite Materials Composite Structures 171 2017: pp. 345-359. https://doi.org/10.1016/j.compstruct.2017.03.025

43. Pour-Ghaz, M., Miller, B.L.H., Khalaf Alla, O., Rizkalla, S. Do Mechanical and Environmental Loading Have a Synergistic Effect on the Degradation of Pultruded Glass Fibre Reinforced Polymers? Composites Part B: Engineering 106 2016: pp. 344-355. https://doi.org/10.1016/j.compositesb.2016.09.007

44. Joliff, Y., Rekik, W., Belec, L., Chailan, J.F. Study of the moisture/stress effects on glass fibre/epoxy composite and the impact of the interphase area Composite Structures 108 2014: pp. 876-885. https://doi.org/10.1016/j.compstruct.2013.10.001

45. Humeau, C., Davies, P., Jacquemin, F. An Experimental Study of Water Diffusion in Carbon/Epoxy Composites Under Static Tensile Stress Composites Part A: Applied Science and Manufacturing 107 2018: pp. 94-104. https://doi.org/10.1016/j.compositesa.2017.12.016

46. Lu, T., Solis-Ramos, E., Yi, Y.-B., Kumosa, M. Synergistic Environmental Degradation of Glass Reinforced Polymer Composites Polymer Degradation and Stability 131 2016: pp. $1-8$. https://doi.org/10.1016/j.polymdegradstab.2016.06.025

47. Fang, Y., Wang, K., Hui, D., Xu, F., Liu, W., Yang, S., Wang, L. Monitoring of Seawater Immersion Degradation in Glass Fibre Reinforced Polymer Composites using Quantum Dots Composites Part B: Engineering 112 2017: pp. $93-102$. https://doi.org/10.1016/j.compositesb.2016.12.043

48. Chen, S., Xu, H., Duan, H., Hua, M., Wei, L., Shang, H., $\mathbf{L i}, \mathbf{J}$. Influence of Hydrostatic Pressure on Water Absorption of Polyoxymethylene: Experiment and Molecular Dynamics Simulation Polymers for Advanced Technologies 28 (1) 2017: pp. 59-65. https://doi.org/10.1002/pat.3858 